\title{
Labour market dynamics in Spanish regions: evaluating asymmetries in troublesome times
}

\author{
Hector Sala • Pedro Trivín
}

Received: 26 April 2013 / Accepted: 25 February 2014 / Published online: 21 March 2014 (C) The Author(s) 2014. This article is published with open access at SpringerLink.com

\begin{abstract}
The Spanish labour market disproportionately booms in expansions and bursts in recessions; meanwhile, its regions' relative position persists: those with the highest unemployment rates in 1996 were also in the worse position in 2012. To examine this twofold feature, we apply Blanchard and Katz's (Brookings Pap Econ Act 1:1-75, 1992) methodology and evaluate how the Spanish labour market reacts to regional employment shocks in a variety of cases. Shock responses are channelled via changes in unemployment, labour market participation, and spatial mobility. Our results provide evidence of asymmetric responses across business cycle phases (19962007 and 2008-2012). While changes in participation rates are the main adjustment mechanism in expansion, unemployment and spatial mobility become the central ones in recession. We also provide evidence of real wage rigidities in both periods, due to rigidities in both nominal wages and consumer prices. We conclude with a cluster analysis showing that high and low unemployment regions have similar responses in the short-run while, in the long-run, the former are more reactive in terms of spatial mobility. Overall, we provide evidence that people in a region are more willing to migrate (relative to the national average) when a regional shock occurs in relatively worse economic contexts.
\end{abstract}

Electronic supplementary material The online version of this article (doi:10.1007/s13209-014-0106-x) contains supplementary material, which is available to authorized users.

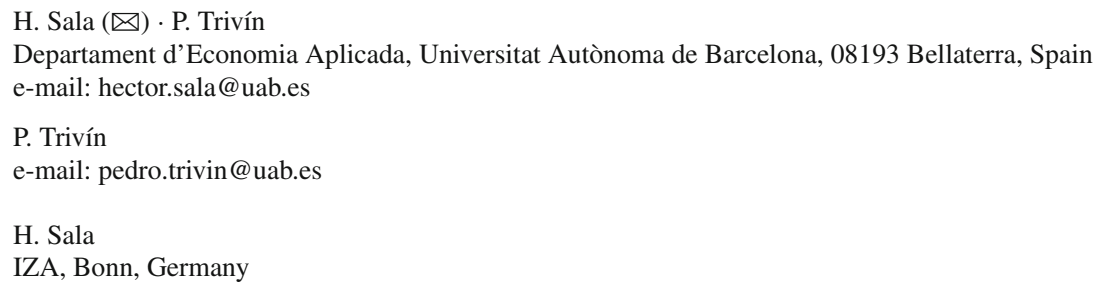


Keywords Employment · Unemployment · Regional labour markets · Spain

JEL Classification $\quad \mathrm{J} 20 \cdot \mathrm{E} 24 \cdot \mathrm{J} 61 \cdot \mathrm{R} 11$

\section{Introduction}

The Great Recession has severely hit Spain in many dimensions. No more than other economies in most of them (economic (de)growth, sovereign debt crisis, banking system collapse), but disproportionately hard on unemployment. After more than a decade trending downwards and converging to the European average, the rate of unemployment reached $8.0 \%$ in 2007-falling from a peak of $24.5 \%$ in 1994 and values above $20 \%$ still in 1996. In 2012, however, after five years of steep rise, the historical maximum was surpassed reaching a massive $26.0 \%$ (Fig. 1).

The intense progress first, and deterioration afterwards, of the Spanish labour market goes in parallel with an extreme degree of regional persistence in labour outcomes. This is illustrated in Fig. 2. Figure 2a shows two groups of regions. The first one with employment growth rates around $-2.5 \%$ in 2008-2012 (with the Balearic Islands and Madrid close to $-2.0 \%$ ), and a second one between -3.3 and $-4.1 \%$. ${ }^{1}$ The difference between the two groups points to the existence of less responsive regions in the North and North-West of Spain (Galicia, Asturias, Castile and Leon, Basque Country, Navarre, Aragon), and more volatile ones in the South and East part of Spain. Madrid (also the Balearic Islands and to some extent Cantabria) would be a salient exception with top employment performance simultaneously in good and bad times. Figure $2 \mathrm{~b}$, in contrast, gives a much homogeneous picture in terms of unemployment rates, with a regression slope of 0.83 and a $R^{2}$ of 0.43 . When combined, the information supplied by Fig. 2a, b discloses two main stylised facts: (i) changes in employment provide just a partial explanation of the evolution of unemployment, and (ii) there is a great persistence in regional unemployment over the years.

These facts and the regional specificity of the Spanish labour market may be studied from a variety of perspectives, taking into account, along the lines of Marston (1985), that changes in regional (un)employment may be the outcome of both national and regional driving forces. Elhorst (2003) distinguishes four types of approaches including single-equation models, implicit models (where he places the Blanchard and Katz model), accounting identity models, and simultaneous-equation models dealing with interactions. The strength of the implicit models are their solid theoretical basis, while simultaneous equation models should be chosen from an empirical viewpoint (Elhorst 2003, p. 741).

Multi-equation structural models have been used in Bande and Karanassou (2009, 2013a,b) to assess to what extent the evolution of differences in Spanish regional unemployment can be attributed to disparities in the respective regional equilibrium unemployment rates or to the evolution of other key variables such as, for example,

1 Given that a simple regression line takes a misleading downward slope, it is not drawn. We should rather think on two upward sloping lines, one per group, indicating that well-performing regions coincide in booms and busts. 


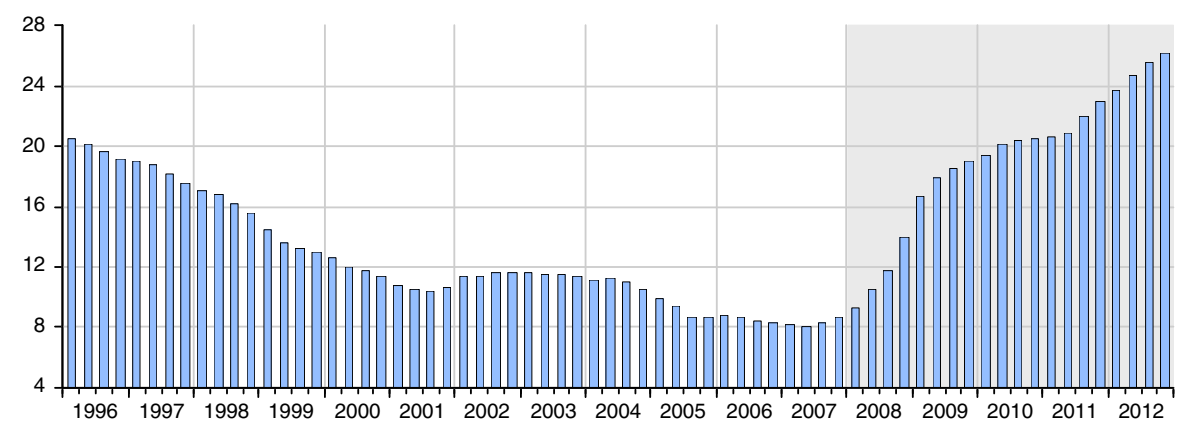

Fig. 1 Quarterly unemployment rate in Spain. 1996-2012. Source Spanish Labour Force Survey (EPA)

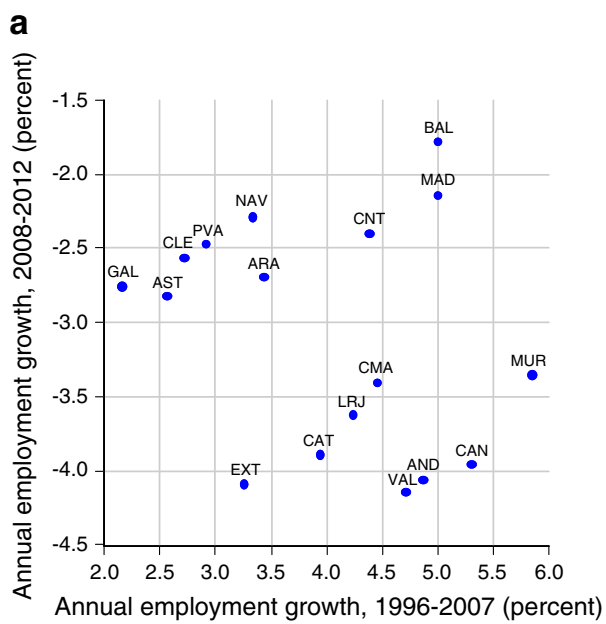

b

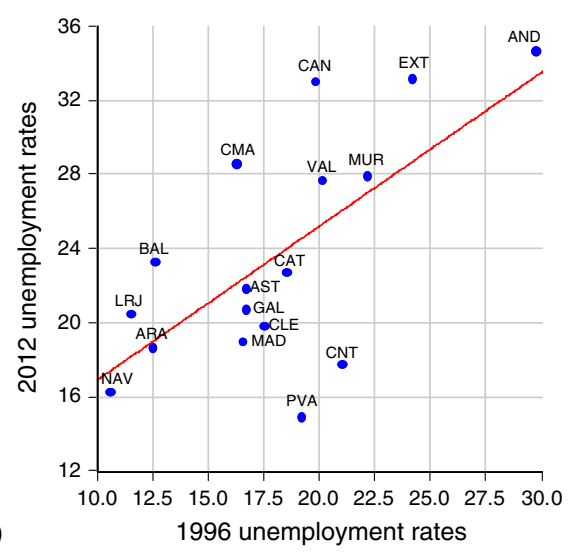

Fig. 2 Labour market performance of Spanish regions. 1996-2012. a Employment growth, b unemployment rates. Source Spanish Labour Force Survey (EPA). AND Andalusia, ARA Aragon, AST Asturias, BAL Balearic Islands, CAN Canary Islands, CNT Cantabria, CLE Castile and Leon, CMA Castile-La Mancha, CAT Catalonia, VAL Valencian Community, EXT Extremadura, GAL Galicia, MAD Community of Madrid, MUR Region of Murcia, NAV Navarre, PVA Basque Country, LRJ La Rioja

capital accumulation. ${ }^{2}$ Our aim, however, is to analyse the regional labour market from a regional specific point of view. It would be too demanding, in our context, to conduct a detailed analysis using their Chain Reaction Theory methodology. The reason is that we consider small sample periods of study, as deserved by the unprecedented specificities of the recent economic developments, at the same time that we need information highly disaggregated by regions. On one side, this causes severe restrictions in terms of degrees of freedom. On the other side, it constrains the analysis to a relatively small number of variables quarterly available for all Spanish regions, and with up-to-date coverage. $^{3}$

2 Other significant articles concerned with Spanish labour market regional disparities are López-Bazo and Motellón $(2012,2013)$ and, with a specific focus on wage setting, Bande et al. $(2008,2010)$.

3 Note that National Accounts data at the regional level are issued with severe delays, and other regional databases, such as the BD-Mores, only cover up to 2007 . Moreover, none of them provide data at quarterly frequencies. 
We are interested in answering questions related to the most recent evolution of the Spanish labour market. What has happened regarding the specific regional responses to labour market shocks? Have they changed relative to previous responses, studied for the period up to the mid 1990s? Are these responses similar in good and bad times? What role do prices play? The framework of analysis developed in Blanchard and Katz (1992) allows us to provide answers to these questions. It yields the possibility of evaluating the impact of employment shocks through the responses they cause, not only in terms of the unemployment rate, but also through changes in participation rates and regional mobility. ${ }^{4}$ Such analysis will enhance our understanding, from a regional perspective, of the labour market adjustment mechanisms in the different scenarios studied.

The model of Blanchard and Katz has been used to investigate the dynamics of regional labour markets in the US (Blanchard and Katz 1992), Europe (Decressin and Fatás 1995), Sweden (Fredriksson 1999), the Netherlands (Broersma and van Dijk 2002), Finland (Mäki-Arvelaa 2003) and, more recently, for the German East-West disparities (Alecke et al. 2010). It has also been used to analyse the Spanish labour market by uncovering its regional persistence in 1976-1994 (Jimeno and Bentolila 1998), and to provide specific analyses on the Southern regions (Murillo et al. 2006) and by level of education (Mauro and Spilimbergo 1999).

Notwithstanding its wide use, it is important to discuss two of its prominent features since it is a model that relies upon (1) the assumption of regional mobility of workers and firms; and (2) the measurement of regional variables as deviations from the national average, which implies that shocks are regionally idiosyncratic.

Regarding the first feature, it is important to show that Blanchard and Katz's model can be safely applied to study the behavior of the Spanish regions in a context of relative low interregional mobility (see Figure 1 in Bover and Arellano (2002)), and relative large international flows, regionally heterogeneous, since the end of the 1990s. In particular, it is important to ensure that our analysis of migration responses to specific shocks are not mixed with demographic changes also affecting the patterns of regional population.

Figure 3 plots the regional relative evolution of interregional and international migration in Spanish regions since $1998 .^{5}$

Figure $3 \mathrm{a}$ shows the average relative internal residential migration rate for each region computed as the ratio of each region's residential migration (across Spanish Autonomous Communities) over total interregional migration. Note that, although there is in general low mobility, regions with a larger relative interregional migration in expansion are also the ones with larger mobility in recession.

\footnotetext{
4 " The feedback effects of the regional unemployment rate on labour supply, labour demand and regional wage-setting in simultaneous equations models dealing with interactions are comparable to those in Blanchard and Katz" (Elhorst 2003, p. 723).

5 For Fig. 3a, the data used is internal residential migrations by region of origin. For Fig. 3b, both international immigration and emigration are considered. We have also checked alternative indicators (such as the internal residential migration by region of destiny, and the flows of international immigration and emigration separately), all yielding very similar results.
} 

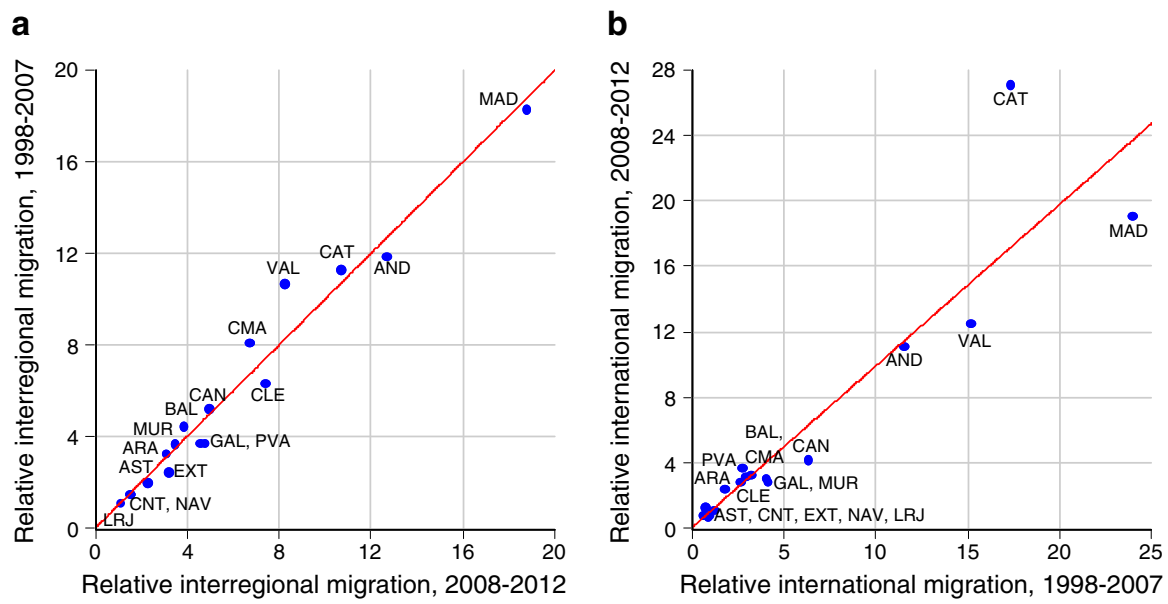

Fig. 3 Relative regional migration in Spanish regions (\%). The sample period is 1998-2012 according to available data. a Relative interregional migration (\%), b relative international migration (\%). Note the complete name of each region is provided in the note below Fig. 2. Source National Statistics Institute (Variaciones Residenciales Interiores y Exteriores)

Figure $3 b$ shows the relative international migration rate computed as the total flows of international migration flowing into and out of each Spanish region over the total flows of international migration in Spain. Note that it is not the relative net inflows what are computed, but the addition of inflows and outflows of international migrants in each region over total international migration flows in Spain. In this way, the computed ratios on relative interregional and international migration are directly comparable. Once again, it can be observed that each region's ratio has remained stable across both periods of analysis.

This analysis, in relative terms, is of course compatible with fluctuations in the absolute values characterized by large net inflows of international migrants during the boom years, especially in the regions with the largest employment growth rates, and the subsequent brake in these flows during the crisis.

It is important to note that these ratios have remained roughly constant between 1998-2007 and 2008-2012 which correspond, broadly, to the two periods of analysis in this work. As there are no important changes in the ratio for each region from one period to another, the regional migration response (both interregional and international) that we estimate and compare across periods is not subject to biases stemming from variations in the regional migration behaviour. ${ }^{6}$

Regarding the fact that we are only evaluating region-specific shocks, we acknowledge that nation-wide shocks may also be relevant, as argued by Bande and Karanassou $(2009,2013 b)$ for other periods. As it will be shown below, however, regional characteristics still play an important role in the determination of the labour market variables. Given that the effects of nation-wide shocks cannot be examined within our

6 The period averages shown in Fig. 3 are not hiding relevant information. Yearly examination of this evolution yields the same conclusion. 
framework, this study should be interpreted as complementary to the existing ones conducted through the estimation of multi-equation models.

In any case, the novelty of our analysis neither lies in the use of Blanchard and Katz's methodology nor is a mere time extension of the work by Jimeno and Bentolila (1998). The paper contributes to the literature in three main dimensions.

One contribution is the specific evaluation of the effects of average regional employment shocks when hitting in expansion and when hitting in recession. For this, we use quarterly data (as Jimeno and Bentolila 1998) and consider two subsample periods: 1996-2007, covering the expansion; and 2008-2012, covering the crisis. This disaggregation allows an evaluation of the asymmetries in shock responses across business cycle phases (upward and downward).

Another key contribution consists in extending the labour market model to include prices. This extension was already present in Blanchard and Katz (1992), but it has generally been disregarded in subsequent literature. Consideration of prices in Spain is a relevant issue both in 1996-2007 and in 2008-2012. In expansion, it allows us to assess the response of wages to the improved economic conditions of the workers. In recession, it allows us to examine to what extent price adjustments have followed the intense quantity adjustments characterising the Spanish economy in recent years. Summing up, we offer new information on how prices respond regionally to labour demand shocks, and the potential asymmetries of these responses in good and bad times.

A third key contribution, finally, is the additional disaggregation by groups of regions based on a cluster analysis. The two resulting groups (one including Catalonia, Madrid, Navarre, and the Basque Country, and the other one grouping the rest of the regions) are used to re-estimate the models and conduct the analysis for the two groups.

Our findings are diverse. First, we identify asymmetric labour market responses across business cycle phases. We find that changes in participation rates are the main adjustment mechanism in expansion, while unemployment becomes the central one in recession. Moreover, the long-run employment impact is larger when the shock hits in a recessive period than when it hits in expansion. This result is an indication that net migration - spatial mobility - is more relevant in troublesome than in good times.

We also provide evidence of real wage rigidities in both periods along the lines of Jimeno and Bentolila (1998). ${ }^{7}$

And there is, finally, evidence of similar labour market dynamics across high and low unemployment regions generated by the one-off employment shocks. This is consistent with the large degree of aggregate (un)employment persistence characterizing Spain, and is to some extent reassuring in the sense that consideration of an average Spanish region is not flawing the results. Nevertheless, we still find differences in the relative long-run regional employment impact and unemployment persistence, resulting on larger spatial adjustments in high than in low unemployment regions, which appear as more resilient to the shock. On this account, it seems safe to conclude that people in a region are more willing to migrate (relative to the national average) not just when regional shocks take place in a recessive period, but also when they impact in places with larger relative unemployment rates.

\footnotetext{
7 Jimeno and Bentolila (1998) uncovered a high degree of persistence in the Spanish regions, as compared to the US and the EU. This was mainly due to real wage rigidities and low interregional migration.
} 
The remaining of the paper is structured as follows. In Sect. 2, we outline the analytical framework and its empirical implementation. In Sect. 3 we present the data used and the econometric methodology. In the following four sections we show our findings related, respectively, to the aggregate analysis, the disaggregation by business cycle phases, the inclusion of price responses, and the consideration of two groups of regions. Section 8 concludes.

\section{Analytical framework}

To conduct our analysis, we use the framework developed in Blanchard and Katz (1992). This framework is derived from a set of equations representative of the average regional labour market within a given economy, and entails the estimation of the following three reduced-form equations:

$$
\begin{aligned}
\Delta n_{i t} & =\lambda_{10}+\lambda_{11}(L) \Delta n_{i t-1}+\lambda_{12}(L) u_{i t-1}+\lambda_{13}(L) p r_{i t-1}+\varepsilon_{i n t}, \\
u_{i t} & =\lambda_{20}+\lambda_{21}(L) \Delta n_{i t}+\lambda_{22}(L) u_{i t-1}+\lambda_{23}(L) p r_{i t-1}+\varepsilon_{i u t} \\
p r_{i t} & =\lambda_{30}+\lambda_{31}(L) \Delta n_{i t}+\lambda_{32}(L) u_{i t-1}+\lambda_{33}(L) p r_{i t-1}+\varepsilon_{i p t}
\end{aligned}
$$

where $n$ is relative employment (in logs), $u$ is the relative unemployment rate (in \%), and $p r$ is the relative participation rate (in logs); $L$ is the lag operator; $i$ stands for region, $t$ for period; the $\lambda^{\prime} s$ are parameters, and the $\varepsilon^{\prime} s$ are residuals.

The term relative affecting $n, u$, and $p r$ indicates the beta-difference of these variables in region $i$ with respect to the national average. More precisely, these three variables are defined as the residuals of the following equations:

$$
\begin{aligned}
\Delta \log \left(N_{i t}\right) & =\alpha_{1 i}+\beta_{i} \Delta \log \left(N_{t}\right)+\mu_{1 i t}, \\
U_{i t} & =\alpha_{2 i}+\gamma_{i} U_{t}+\mu_{2 i t}, \\
\log \left(P R_{i t}\right) & =\alpha_{3 i}+\delta_{i} \log \left(P R_{t}\right)+\mu_{3 i t},
\end{aligned}
$$

where $N, U$ and $P R$ denote employment, the unemployment rate and the participation rate (all in absolute values); and $\beta_{i}, \gamma_{i}, \delta_{i}$ account for the regional sensitivity of these three variables with respect to changes in their national counterpart. The $\alpha^{\prime} s$ are the regional constants, whereas the $\mu^{\prime} s$ are the corresponding residuals.

In computing the values of the relative variables $n, u$, and $p r$ as beta-differences, we follow the same methodology than Decressin and Fatás (1995) and Broersma and van Dijk (2002), who also use the residuals from Eqs. (4)-(6). It is important to note that, by creating relative variables through beta-differenciation, we isolate the part of the variation in the regional variable that is not due to national changes. Each region is thus allowed to respond differently to a national shock. This is a situation empirically relevant whenever the beta coefficients— $\beta_{i}, \gamma_{i}, \delta_{i}$ in Eqs. (4)-(6)—are significantly different from unity.

This procedure, however, is not the only possibility at hand, and a decision needs to be taken on the basis of the intended analysis to be performed. The alternative followed by Blanchard and Katz (1992) and Jimeno and Bentolila (1998) is to create regional 
specific variables as the log-difference between the regional and the national ones. ${ }^{8}$ In this case, relative variables are not just considering regional responses to asymmetric shocks, but also regional asymmetric responses to common shocks. ${ }^{9}$

Another useful piece of information delivered by Eqs. (4)-(6) is their adjusted $R^{2}$ 's. Taking as example Eq. (4), note that the value of this coefficient indicates the extent to which the pattern of regional employment growth fits the pattern of employment growth at the national level. For example, low values of the adjusted $R^{2}$ 's show that most movements in regional employment are not driven by national changes in labour demand. For the whole sample of our analysis (1996-2012), the average adjusted $R^{2}$ is 0.48 implying that just half of the regional employment growth variation can be explained, on average, by national trends.

Summing up, this methodology involves, first, the estimation of Eqs. (4)-(6); and, second, the use of the residuals as relative variables to estimate the system of Eqs. (1)-(3).

Once this process is completed, we shock the system with a one-off shift in the residual of Eq. (1). Such unexpected and temporary shocks on employment growth are the ones evaluated in our analysis. It is important to note that, when we examine the dynamics of these shocks, we are not evaluating the persistence in the average value of the variable under scrutiny (no matter whether this is the employment growth or the unemployment and participation rates). What we are checking, rather, is the speed of convergence of this variable to the previous equilibrium, wherever this one is. This means that these shocks can be formally introduced as positive shocks in all cases, even if their effects are evaluated for a sample period just containing recessive years (as we do later on).

The interpretation of the effects of the shock is made under two common assumptions in the literature. The first one is that unexpected changes in regional relative employment within a year are due to changes in labour demand. This assumption is considered to be correct when most year-to-year unexpected movements in employment are caused by shifts in labour demand rather than shifts in labour supply. This is arguably the case in Spain in the last business cycle.

The second assumption concerns the identification of the shock. It states that employment growth is independent of current changes in the unemployment and participation rates, whereas these rates respond contemporaneously to changes in employment. Jimeno and Bentolila (1998) note that this assumption is more likely to hold when using quarterly data than when using annual data, which is precisely the case here.

When the shock takes place, it gives rise to three adjustment mechanisms, two of them directly arising from the estimated model, and a third one computed as a residual. ${ }^{10}$ The first two arise from Eqs. (2) and (3), where the reactions in termsof

\footnotetext{
8 Although our main analysis is based on the results obtained when taking beta-differences, the online appendix provides the same set of results obtained on the basis of log-differencing the variables. It is important to note that both deliver the same qualitative picture, even though each sets of results requires its own assessment.

9 See L'Angevin (2007) for a detailed explanation on the interpretation of different 'relative' regional variables.

10 Alecke et al. (2010) augment Blanchard and Katz's (1992) model with a migration equation. Unfortunately, data on migrations is not available for Spain at quarterly frequencies.
} 
unemployment and participation rates take place. By construction of the model, any employment stimulus not absorbed by a decrease in unemployment or an increase in participation can be ascribed to spatial mobility. Mobility is thus the third adjustment mechanism, and is computed as the difference between the overall employment response to the shock and the unemployment and participation rates responses.

Blanchard and Katz (1992) consider an extension of the basic labour market model where price responses are also evaluated. This requires the addition, to the system of Eqs. (1)-(3), of the following price equation:

$$
w_{i t}=\lambda_{40}+\lambda_{41}(L) \Delta n_{i t}+\lambda_{42}(L) u_{i t-1}+\lambda_{43}(L) p r_{i t-1}+\lambda_{44}(L) w_{i t-1}+\varepsilon_{i w t},
$$

where $w_{i t}$ represents two different price variables depending on the estimated model: nominal wages (in our case, the hourly total labour cost) and consumer prices (the standard CPI). ${ }^{11}$ We consider this addition because it sheds new light on the price behaviour in the aftermath of average regional shocks in good and bad times.

We endeavour to examine price responses in Spain because of the conspicuous link between labour market prices and quantities. It is on this account that we incorporate nominal wages and a price deflator to the analysis. Jimeno and Bentolila (1998) had already dealt with this issue by examining the wage response to local economic conditions in 1983-1988. They found " a low responsiveness of wages to regional economic conditions" in which nominal wages were less flexible than prices. Here, we retake this issue, but sticking to Blanchard and Katz's (1992) methodology.

\section{Data and estimation issues}

As noted, we first need to estimate Eqs. (4), (5) and (6), and then Eqs. (1), (2) and (3). The first set of equations consist on a time-series estimation by Ordinary Least Squares (OLS), whereas the second set of equations calls for the use of Panel Vector AutoRegression (PVAR) techniques estimated by System OLS.

\subsection{Data}

Information on the labour market variables (employment, participation rate, and unemployment rate) is obtained from the Labour Force Survey (Encuesta de Población Activa, EPA, from its Spanish acronym). In turn, information on the labour and product prices variables comes, respectively, from the Quarterly Survey of Labour Costs (Encuesta Trimestral de Coste Laboral, ETCL) and the National Statistics Institute (Instituto Nacional de Estadística, INE). Table 1 presents the notation, sources and available sample periods for each of these variables.

The Labour Force Survey underwent a methodological change, in 2002, affecting the definitions of unemployment and participation rates. Since our study departs from 1996 (coinciding with the previous methodological change) to cover at length the last

11 Further to the addicion of Eq. (7), note that consideration of an aditional variable in the model implies the addition of the term $\lambda_{4}(L) w_{i t-1}$ in each of the equations in model (1)-(3). 
Table 1 Definitions of variables

\begin{tabular}{llll}
\hline & Variables & Sources & Time period \\
\hline Labour market & & & \\
$N_{i t}$ & Employment & EPA & 1996q1-2012q4 \\
$P R_{i t}$ & Participation rate & EPA & $1996 \mathrm{q} 1-2012 \mathrm{q} 4$ \\
$U_{i t}$ & Unemployment rate & EPA & 1996q1-2012q4 \\
$P r i c e s$ & & & \\
$T C_{i t}$ & Hourly total labour costs & ETCL & 2000q1-2012q3 \\
$C P I_{i t}$ & Consumer prices index & INE & $1996 \mathrm{q} 1-2012 \mathrm{q} 4$ \\
\hline
\end{tabular}

business cycle (1996-2012), we need to construct homogeneous series. We do that using the official link coefficients supplied by the INE itself, and use the resulting series in our analysis.

From the ETCL we obtain the effective hourly total labour cost $T C$, which we think it is the relevant variable when examining how sensitive factor prices are to labour market shocks. The $T C$ is the gross cost paid by the employer taking into account any other cost beyond the wage. Note that this variable has a shorter sample size starting in $2000 q 1$ and finishing in $2012 q 3$. The variable for prices, $C P I$, is the standard consumer price index.

All our variables are disaggregated regionally, have quarterly frequencies, and are seasonally adjusted by using the US X12 Census Bureau process.

\subsection{Estimation methodology}

The PVAR econometric model to be estimated takes the following reduced form in matrix notation: ${ }^{12}$

$$
\mathbf{y}_{i, t}=\Gamma_{0}+\Gamma_{1}(L) \mathbf{y}_{i, t-1}+\varepsilon_{i t},
$$

where $y_{i, t}$ is the vector of endogenous variables (in our case $y_{i, t}=\Delta n_{i t}, u_{i r}, p r_{i t}$ ), $\Gamma_{1}(L)$ is a matrix of the reduced form coefficients relating past variable values to current values, $\Gamma_{0}$ is a vector of constants, and $\varepsilon_{i t}$ is a vector of idiosyncratic errors.

Since our relative variables are created by orthogonalizing the regional variables with respect to the national average, there is no reason for fixed effects to be introduced in the estimated equations. This alleviates our estimates from the well-known dynamic panel data estimation problems, and allows us to proceed with System OLS, rather than System GMM, estimation. ${ }^{13}$

\footnotetext{
12 We estimate a PVAR(2). The lag order of the PVAR is chosen to use the maximum sample period available without neglecting the relevance of dynamics. For robustness, the PVAR has been estimated using different lag orders. The results remain roughly the same and are available upon request.

13 System GMM estimates of the PVAR models with fixed effects are provided in Sala and Trivín (2013). However, System GMM is a more inefficient estimation method in our context. We owe this point to an anonymous referee who made us note that fixed effects were already introduced when defining the relative variables and, thus, were no longer required when estimating. It is worth noting, also, that our findings are robust across econometric methodologies.
} 
Table 2 Results on Moran's I test

\begin{tabular}{|c|c|c|c|c|c|c|c|c|}
\hline & \multicolumn{4}{|c|}{$1 \%$ critical value } & \multicolumn{4}{|c|}{$5 \%$ critical value } \\
\hline & \multicolumn{2}{|c|}{ 1996-2007 } & \multicolumn{2}{|c|}{ 2008-2012 } & \multicolumn{2}{|c|}{ 1996-2007 } & \multicolumn{2}{|c|}{ 2008-2012 } \\
\hline & \# periods & $\%$ & \# periods & $\%$ & \# periods & $\%$ & \# periods & $\%$ \\
\hline$\Delta n_{i t}$ & $1 / 47$ & 2.1 & $0 / 19$ & 0.0 & $5 / 47$ & 10.6 & $0 / 19$ & 0.0 \\
\hline$u_{i t}$ & $2 / 48$ & 4.2 & $0 / 20$ & 0.0 & $10 / 48$ & 20.8 & $0 / 20$ & 0.0 \\
\hline$p r_{i t}$ & $1 / 48$ & 2.1 & $0 / 20$ & 0.0 & $5 / 48$ & 10.4 & $2 / 20$ & 10.0 \\
\hline$t c_{i t}$ & $1 / 32$ & 3.1 & $0 / 19$ & 0.0 & $3 / 32$ & 9.4 & $2 / 19$ & 10.5 \\
\hline$c p i_{i t}$ & $6 / 48$ & 12.5 & $1 / 20$ & 5.0 & $14 / 48$ & 29.2 & $1 / 20$ & 5.0 \\
\hline
\end{tabular}

Detailed test results are available from the authors upon request

Once the estimation is performed, we compute impulse-response functions (IRFs) describing the reaction of the dependent variables to changes in the innovation of one particular variable in the estimated system. Following the model of Blanchard and Katz this variable is employment growth. We will thus evaluate the dynamics of the labour market to one-off shocks in regional employment. ${ }^{14}$

\subsection{Spatial dependence}

Regional variables may be liable to spatial correlation even though, in our study, the potential incidence of this problem should be lessened by the fact that national averages are subtracted from the regional values. Nevertheless, in order to discard that the regional distribution of each variable in the model is not random, and thus causes biased and inconsistent results, we run Moran's I test (Moran 1950).

We construct a binary contiguity weighting matrix $\mathbf{W}$ in which the $i, j$ elements (corresponding to the relative position of region $i$ with respect to region $j$ ) take value $1, \bar{w}_{i j}=1$, if the involved regions share their borders, at least partially; and take value $0, \bar{w}_{i j}=0$, otherwise. We then standardise $\mathbf{W}$ so that the rows add up to unity and regions with a small number of borders do not have excessive weights.

For each quarter in our sample, we conduct the two tail version of the test so that the null hypotheses of randomness (i.e., no spatial dependence) is contrasted against the alternative of no randomness (or spatial correlation). Table 2 reports the results we obtain for all variables of interest at the 1 and $5 \%$ critical values. The information shown is the number of periods for which the null of randomness is rejected and the corresponding percentage over the total number of quarters in each subsample period.

Regarding the labour market variables, there is no indication of serious spatial dependence. In the worst case, the unemployment rate variable examined at the $5 \%$ critical value in 1996-2007, we cannot reject the null of randomness in 38 out of 48 quarters. Then, with respect to prices, we can safely discard regional correlation at

14 All PVAR models in this paper are estimated by using the package provided by Ryan Decker, which is an update of the original package developed by Inessa Love and used in Love and Zicchino (2006). 
the $1 \%$ critical value. It is important to note that these results are consistent with the reported findings in Bande and Karanassou (2013b) for labour market variables using annual data between 1980 and 2000 .

\subsection{Panel unit root tests}

Another important issue is the potential presence of unit roots in the variables. Hence, to check the validity of our estimation we have to prove that stationary panel data techniques are appropriate given the integration order of our variables.

To do that, we conduct a series of panel unit root tests. Although it is well-known that the popular individual unit root tests-Dickey-Fuller (DF), Augmented DickeyFuller (ADF), and Phillips-Perron (PP) tests-have limited power in distinguishing the null of a unit root from stationary alternatives with highly persistent deviations from equilibrium, it is also generally accepted that the use of pooled cross-section time series data can generate more powerful unit root tests (Levin et al. 2002).

Taking this into account, we conduct a series of panel unit tests to check if the use of stationary panel data estimation techniques is appropriate in our context. We thus carry out the statistic test proposed by Maddala and Wu (1999), which is an exact nonparametric test based on Fisher (1932):

$$
\zeta=-2 \sum_{i=1}^{N} \ln \pi_{i} \sim \chi^{2}(2 N)
$$

where $\pi_{i}$ is the probability value of the ADF unit root test for the $i$ th unit (region in our case).

This test has the following attractive characteristics: (i) it does not restrict the autoregressive parameter to be homogeneous across $i$ under the alternative of stationarity; and (ii) the choice of the lag length and the inclusion of a time trend in the individual ADF regressions can be determined separately for each region.

Table 3 shows the results of Maddala and Wu (1999) unit root tests for our 5 variables of interest. The test statistic, $\zeta$, follows a Chi squared distribution, which in our case has a $5 \%$ critical value of approximately 49 . It is easy to see that all the panel unit root test statistics are greater than the critical value, and the null of a unit root can therefore be rejected at the $5 \%$ significance level. It is thus safe to proceed with the analysis by applying stationary panel data techniques. ${ }^{15}$

\section{Aggregate results}

We start by presenting an aggregate picture along the lines of previous literature. It comprises the whole sample period, does not yet consider prices, and all regions are

\footnotetext{
15 Note that we only present a selection of test results, which correspond to some specific periods and do not cover entirely the estimated models in Sects. 4, 5, 6 and 7. Results for the whole sample period and all regions, and for the whole sample period and the high and low unemployment groups of regions, follow the same pattern. They are available upon request.
} 
Table 3 Panel unit root tests

\begin{tabular}{lcrrrr}
\hline & $\zeta\left(\Delta n_{i t}\right)$ & $\zeta\left(u_{i t}\right)$ & $\zeta\left(p r_{i t}\right)$ & $\zeta\left(c p i_{i t}\right)$ & $\zeta\left(t c_{i t}\right)$ \\
\hline $96-07$ & 557.23 & 104.72 & 122.08 & 63.88 & \\
$08-12$ & 175.21 & 73.81 & 67.49 & 86.65 & 237.93 \\
$00-07$ & 319.66 & 100.10 & 111.71 & & 176.03 \\
$08-12^{\mathrm{a}}$ & 202.44 & 70.98 & 58.73 & & \\
\hline
\end{tabular}

$\zeta$ (.) is the test proposed by Maddala and Wu (1999). It follows a Chi square distribution whose $5 \%$ critical value is 48.6. Lower case letters denote relative variables

a The data here runs from $2008 \mathrm{q} 1$ to $2012 \mathrm{q} 3$ due to data limitations in $t c_{i t}$

Table 4 Summary of estimates 1996-2012

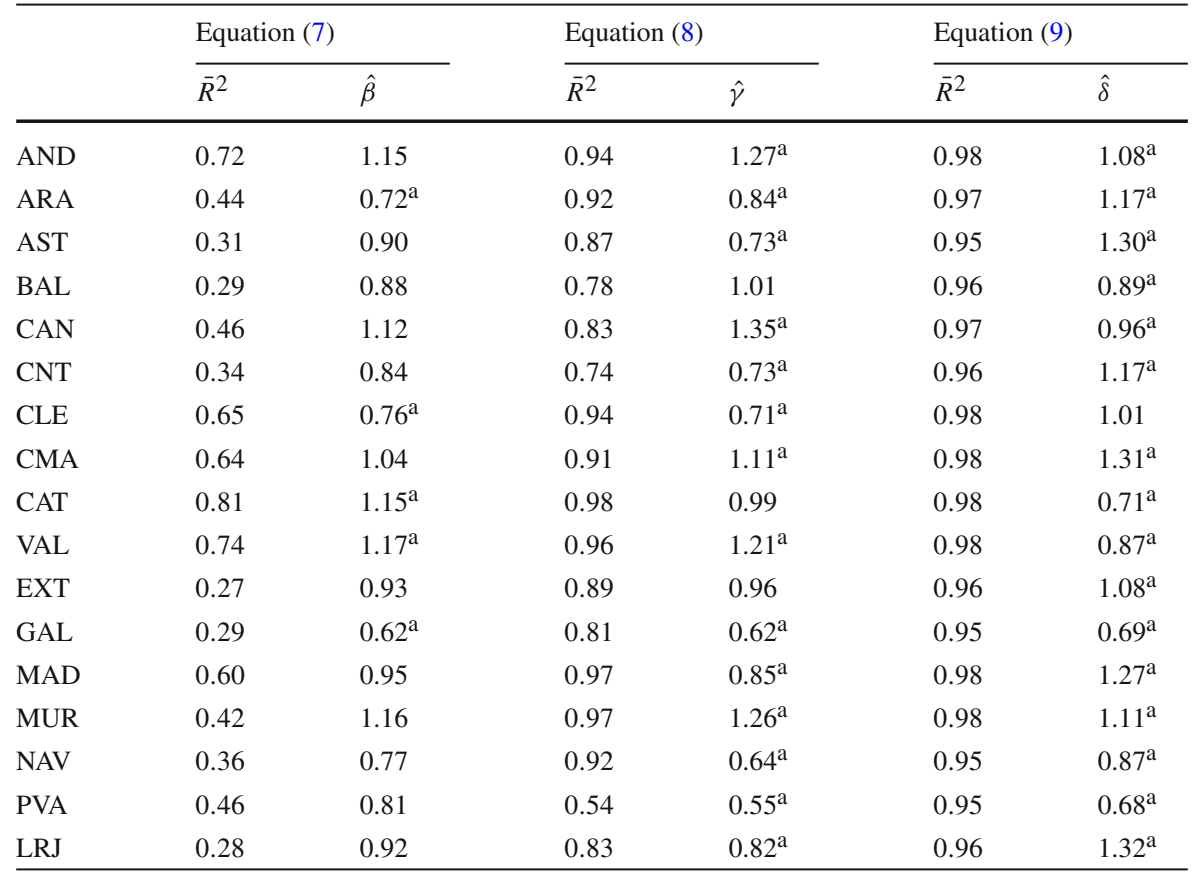

${ }^{\text {a }}$ Indicates $\hat{\beta}, \hat{\gamma}$ and $\hat{\delta}$ are different from unity at a $5 \%$ critical value; for the list of regions, see the notes below Fig. 2

taken into account. These three issues - splitting the sample, considering prices, and grouping the regions-will be faced in subsequent sections.

Table 4 shows the estimated $\beta, \gamma$ and $\delta$ s, together with the corresponding adjusted $R^{2}$ s for the regional regressions of Eqs. (4), (5), and (6) corresponding to years 19962012.

We find the estimates of $\beta$ to be significantly different from unity (at a $5 \%$ critical value) in 5 out of 17 regions. In contrast, the estimates of $\gamma$ and $\delta$ are significantly different from unity in 14 and 16 regions respectively. In view of these results, we create the regional specific variables allowing regions to respond differently to common shocks. 

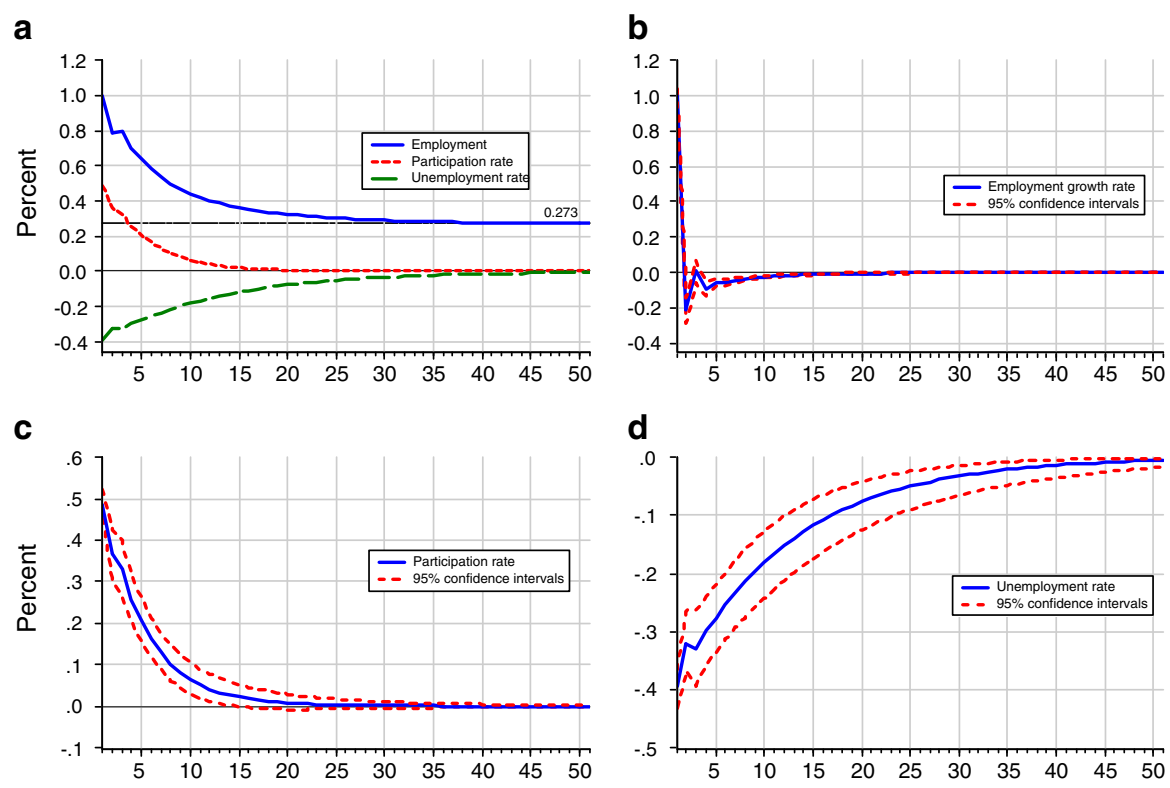

Fig. 4 Aggregate IRFs to a regional employment shock 1996-2012. a Normalised, b Employment growth rate, $\mathbf{c}$ Participation rate, $\mathbf{d}$ Unemployment rate

The values of the adjusted $R^{2}$ s corresponding to Eq. (4) provide a measure of the relevance of the regional shocks vis-à-vis the national ones. The fact that this value is below 0.50 in 11 out of 17 territories is an indication that regional-shocks are very relevant for the understanding of the Spanish labour market behaviour.

The residuals from these estimated equations are used to examine the aggregate impulse responses to a regional labour demand shock. These are plotted in Fig. 4. Figure 4a shows the reaction of the average Spanish region to this shock in terms of employment, and the participation and unemployment rates. Employment converges to 0.273 indicating that $27.3 \%$ of the one-off shock is translated into a larger, longrun, relative regional employment level, which is covered by an increase in population (spatial mobility). The rest of the shock is absorbed by the growing participation rates and falling unemployment rates.

It should be noted that Fig. 4a provides normalised responses to the shock, while Fig. 4b-d deliver the original impulse-response functions, together with their standard errors. The reason for normalising is that the IRFs are calculated on one standard deviation shocks and may deliver small divergences from unity. We normalise to ensure comparability across results in next sections. The standard errors are calculated using Monte Carlo simulations with 500 replications. ${ }^{16}$

Figure 4a is directly comparable to Figure 2 in Jimeno and Bentolila (1998), and yields a similar picture both in terms of the labour market dynamics generated by the

\footnotetext{
16 To conserve space, for the rest of the analysis we only show our results in terms of the normalised impulse-response functions.
} 
Table 5 IRFs decomposition to a $1 \%$ regional employment shock

\begin{tabular}{|c|c|c|c|c|c|c|}
\hline & \multicolumn{3}{|c|}{ Spain $(1976-94)^{\mathrm{a}}$} & \multicolumn{3}{|c|}{ Spain (1996-2012) } \\
\hline & $\begin{array}{l}\text { Participation } \\
(\%)\end{array}$ & $\begin{array}{l}\text { Unemployment } \\
(\%)\end{array}$ & $\begin{array}{l}\text { Migration } \\
(\%)\end{array}$ & $\begin{array}{l}\text { Participation } \\
(\%)\end{array}$ & $\begin{array}{l}\text { Unemployment } \\
(\%)\end{array}$ & $\begin{array}{l}\text { Migration } \\
(\%)\end{array}$ \\
\hline Year 1 & 23 & 36 & 41 & 43 & 41 & 16 \\
\hline Year 2 & 18 & 39 & 43 & 26 & 43 & 31 \\
\hline Year 3 & 18 & 33 & 49 & 14 & 40 & 46 \\
\hline
\end{tabular}

Quarterly data aggregated to annual values and normalised by the employment response in the year

${ }^{a}$ Results taken from Jimeno and Bentolila (1998), p. 33

shock, and in terms of its employment effect. They place this effect at 0.40, while Decressin and Fatás (1995) place it at 0.60 for the European Union.

Table 5 provides a detailed comparison of the way a stylised region responds to a regional employment shock today (1996-2012) with its reaction in the past (19761994). The main differences observed are the following. First, adjustments via changes in participation rates are much more relevant today than in the past, especially in the short-run (43 vs. $23 \%$ in the first year). However, there is a much lower persistence today causing the adjustment in the participation rate to fall by 4 percentage points in 1996-2012 relative to years 1976-1994. Second, unemployment displays slightly larger values and persistence today than in the past. The larger incidence of the participation and unemployment rate channels leaves spatial mobility as a minor adjustment mechanism in the short-run. In the long-run, however, quick convergence in participation allows migration to stay as relevant, today, as it was in the past (49 vs. $46 \%)$.

\section{Labour market dynamics during the 'wild-ride' and the 'steep-fall' periods}

So far we have studied the dynamics of the average region for the whole last business cycle. Some authors, however, have come out with the idea that some Spanish regional unemployment features (e.g. regional disparities) are related with the different phases of the business cycle (Bande et al. 2008). Accordingly, this section aims at examining regional-specific dynamic adjustment mechanisms when a positive shock hits the economy in good and bad times.

Table 6 shows the estimated $\beta \mathrm{s}, \gamma \mathrm{s}, \delta \mathrm{s}$, and the corresponding adjusted $R^{2} s$ for the regional regressions of Eqs. (4), (5) and (6) conducted for two subsample periods: 1996-2007, corresponding to the 'wild-ride' of the Spanish economy during those years, and 2008-2012, corresponding to the subsequent steep fall. We acknowledge the fact that these estimates may be sensitive to the sample period length. However, they correspond to such specific and contrasted developments that it is worth examining them individually. Moreover, in order to discard biases, next section provides two robustness checks related to the shortening of the first sub-sample period (to 20002007 due to data availability in the total labour costs variable) and to the addition of different price variables to the system. As we will see, the results are robust to these changes. 
Table 6 Key estimates for Eqs. (4), (5) and (6)

\begin{tabular}{|c|c|c|c|c|c|c|c|c|c|c|c|c|}
\hline & \multicolumn{6}{|c|}{ 1996-2007 } & \multicolumn{6}{|c|}{ 2008-2012 } \\
\hline & $\bar{R}^{2}$ & $\hat{\beta}$ & $\bar{R}^{2}$ & $\hat{\gamma}$ & $\bar{R}^{2}$ & $\hat{\delta}$ & $\bar{R}^{2}$ & $\hat{\beta}$ & $\bar{R}^{2}$ & $\hat{\gamma}$ & $\bar{R}^{2}$ & $\hat{\delta}$ \\
\hline AND & 0.23 & 1.39 & 0.94 & $1.51^{\mathrm{a}}$ & 0.98 & $0.95^{\mathrm{a}}$ & 0.51 & 0.84 & 0.99 & $1.23^{\mathrm{a}}$ & 0.47 & $2.52^{\mathrm{a}}$ \\
\hline ARA & -0.01 & $0.24^{\mathrm{a}}$ & 0.88 & $0.62^{\mathrm{a}}$ & 0.96 & $1.16^{\mathrm{a}}$ & 0.07 & $0.46^{\mathrm{a}}$ & 0.96 & $0.87^{\mathrm{a}}$ & -0.04 & -0.49 \\
\hline AST & 0.06 & 1.25 & 0.83 & $0.74^{\mathrm{a}}$ & 0.91 & $1.17^{\mathrm{a}}$ & 0.30 & 1.18 & 0.96 & 0.97 & -0.06 & -0.04 \\
\hline BAL & 0.04 & 0.98 & 0.63 & $0.48^{\mathrm{a}}$ & 0.95 & $0.91^{\mathrm{a}}$ & 0.06 & 0.82 & 0.93 & 0.98 & 0.05 & 1.20 \\
\hline CAN & 0.13 & 1.45 & 0.86 & $0.77^{\mathrm{a}}$ & 0.96 & 0.98 & 0.28 & 1.25 & 0.98 & $1.16^{\mathrm{a}}$ & 0.11 & 1.94 \\
\hline CNT & -0.003 & 0.55 & 0.97 & $1.18^{\mathrm{a}}$ & 0.94 & $1.24^{\mathrm{a}}$ & 0.02 & $0.35^{\mathrm{a}}$ & 0.99 & $0.77^{\mathrm{a}}$ & -0.05 & -0.28 \\
\hline CLE & 0.22 & 0.99 & 0.98 & $0.88^{\mathrm{a}}$ & 0.97 & $0.93^{\mathrm{a}}$ & 0.41 & $0.62^{\mathrm{a}}$ & 0.99 & $0.75^{\mathrm{a}}$ & 0.24 & 1.40 \\
\hline CMA & 0.03 & 0.54 & 0.96 & $0.71^{\mathrm{a}}$ & 0.98 & $1.21^{\mathrm{a}}$ & 0.33 & 0.92 & 0.98 & $1.21^{\mathrm{a}}$ & 0.20 & 1.80 \\
\hline CAT & 0.27 & 1.13 & 0.97 & 1.02 & 0.99 & $0.77^{\mathrm{a}}$ & 0.80 & $1.46^{\mathrm{a}}$ & 0.99 & 0.99 & -0.05 & 0.20 \\
\hline VAL & 0.14 & 0.90 & 0.96 & 1.002 & 0.99 & $0.94^{\mathrm{a}}$ & 0.56 & 1.12 & 0.98 & $1.14^{\mathrm{a}}$ & 0.01 & $-0.91^{\mathrm{a}}$ \\
\hline EXT & 0.04 & 1.05 & 0.89 & 0.93 & 0.95 & 1.04 & 0.04 & 0.88 & 0.90 & $1.23^{\mathrm{a}}$ & 0.11 & 2.24 \\
\hline GAL & 0.03 & 0.69 & 0.83 & $0.71^{\mathrm{a}}$ & 0.92 & $0.65^{\mathrm{a}}$ & 0.05 & 0.44 & 0.96 & $0.87^{\mathrm{a}}$ & 0.26 & 1.37 \\
\hline MAD & 0.11 & 0.90 & 0.95 & $0.91^{\mathrm{a}}$ & 0.98 & $1.37^{\mathrm{a}}$ & 0.38 & 1.03 & 0.98 & $0.76^{\mathrm{a}}$ & 0.15 & 1.11 \\
\hline MUR & -0.002 & 0.61 & 0.96 & $1.15^{\mathrm{a}}$ & 0.96 & $1.08^{\mathrm{a}}$ & 0.12 & 0.87 & 0.97 & $1.15^{\mathrm{a}}$ & 0.31 & 1.55 \\
\hline NAV & 0.16 & 1.27 & 0.86 & $0.49^{\mathrm{a}}$ & 0.94 & 0.97 & 0.03 & 0.59 & 0.95 & $0.67^{\mathrm{a}}$ & 0.02 & $-0.72^{\mathrm{a}}$ \\
\hline PVA & 0.11 & 0.92 & 0.98 & $1.10^{\mathrm{a}}$ & 0.98 & $0.79^{\mathrm{a}}$ & 0.26 & 1.04 & 0.94 & $0.59^{\mathrm{a}}$ & -0.03 & 0.42 \\
\hline LRJ & 0.07 & 1.27 & 0.73 & $0.46^{\mathrm{a}}$ & 0.95 & $1.43^{\mathrm{a}}$ & -0.06 & -0.01 & 0.91 & 0.91 & -0.03 & 0.58 \\
\hline
\end{tabular}

a Indicates $\hat{\beta}, \hat{\gamma}$ and $\hat{\delta}$ are different from unity at a $5 \%$ critical value; for the list of regions, see the notes below Fig. 2

The first salient finding is the relatively large adjusted $R^{2} \mathrm{~S}$ of Eq. (4) for years 2008 2012, in contrast to the low ones for 1996-2007. This is an indication that nation-wide shocks have become more relevant during the steep-fall years, and is consistent with the fact that Spain was fully caught by the Great Depression, which has driven all regions to an unprecedented slump. The few cases, not infrequent in the literature (see Decressin and Fatás 1995), in which the adjusted $R^{2}$ s fall around zero reveal the prominence of regional shocks.

A second noticeable result concerns the change in the participation rate behaviour. There is a stark contrast between the values of the adjusted $R^{2}$ in the first period (above 0.90 in all regressions) and the second one (in which they become low). To discard the possibility that this is due to the short sample period of 2008-2012, we shortened the first period to 2003-2007 to take the same length. Since the results remained essentially unchanged, we credit the hypothesis that regional participation rates have radically changed their behaviour. A behaviour that was mainly determined at the national level but has become regionally specific. This finding reinforces our strategy of disaggregating the analysis in subperiods.

As before, we shock the estimated systems and compute the resulting IRFs for each period of analysis. These are shown in Fig. 5.

The long-run impact of the shock on the relative regional level of employment is smaller in 1996-2007 than in 2008-2012. This reflects the enhanced spatial 

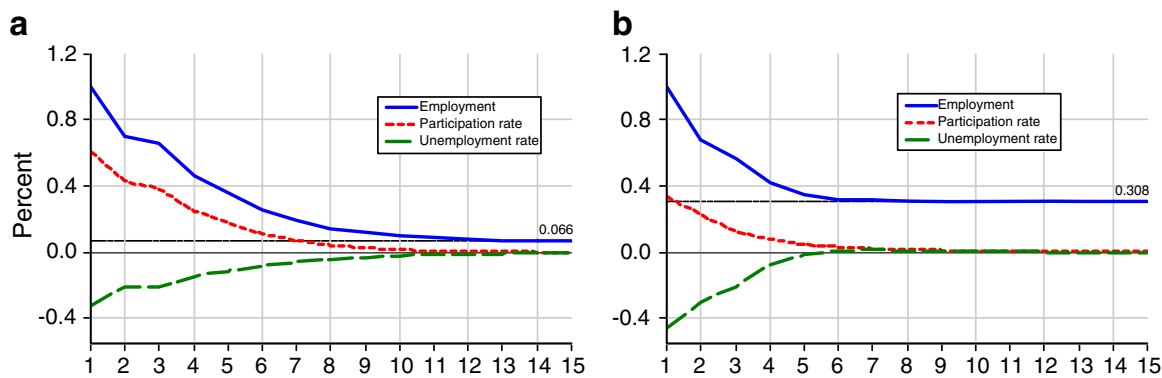

Fig. 5 IRFs to a regional employment shock in 1996-2007 and 2008-2012. a 1996-2007, b 2008-2012

Table 7 IRFs decomposition to a $1 \%$ regional employment shock

\begin{tabular}{llc}
\hline & $1996-2007(\%)$ & $2008-2012(\%)$ \\
\hline Final employment effect & 0.07 & 0.31 \\
Adjustment in 1st quarter by & & \\
Participation & 60.5 & 33.4 \\
Unemployment & 32.5 & 46.3 \\
Migration & 7.0 & 20.3 \\
Cumulative adjustment in 15th quarter by & & \\
Participation & 48.5 & 14.8 \\
Unemployment & 29.8 & 16.8 \\
Migration & 21.7 & 68.4 \\
\hline
\end{tabular}

mobility during the crisis, people in a region being more willing to migrate (relative to the national average) when there is a regional shock in bad times than when the shock impacts in good times. On top of these differences in the adjustment mechanisms across periods, persistence in the participation and unemployment rates responses is somewhat reduced in 2008-2012, when they take around $6 / 7$ quarters, rather than 9 , to converge to equilibrium. This result contrasts with the larger persistence of these variables (close to 20 and 35 quarters, respectively) when all years in the sample are examined together. This is mainly due to the analysis of much more homogeneous periods when the full sample is split in expansionary and recessive years, than when both subsamples are considered together (see Altissimo et al. 2009).

Regarding the decomposition of the different components in terms of their influence on the adjustment process, Table 7 shows the large response of relative regional participation rates in 1996-2007. It explains around $60 \%$ of the adjustment in the first quarter, and still accounts for more than $48 \%$ of it in quarter 15 . In contrast, the immediate response of unemployment dominates in 2008-2012 (more than $45 \%$ versus less than a third the participation rate response), although it vanishes progressively. The picture at the end is one of stark differences across periods. While adjustments during the wild ride are distributed more homogeneously with a dominant participation rate mechanism, during the crisis it is migration, by far, what leads the adjustment. 

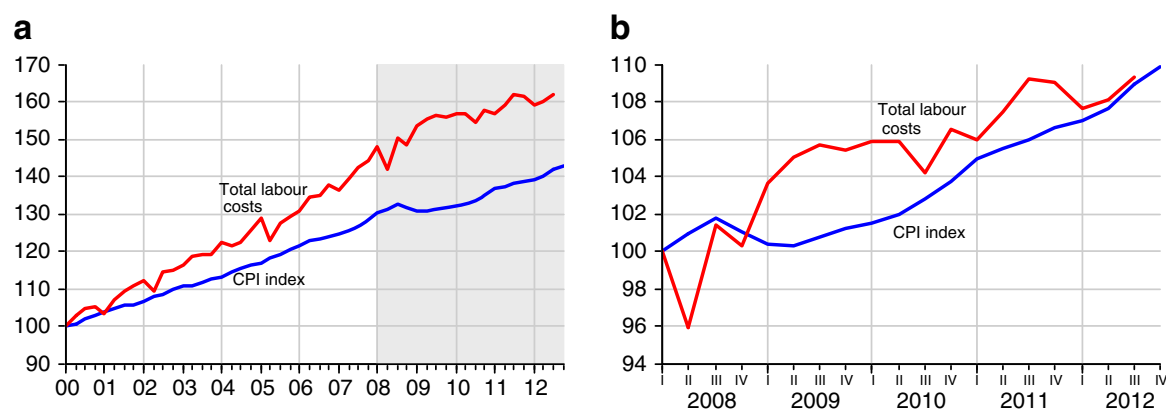

Fig. 6 Product and labour market prices. Index 100. a 2000-2012, b 2008-2012

\section{Price responses}

Price rigidities are an important area of interest in macroeconomics and labour economics. In this section we enquire to which extent they are also relevant at the regional level. To outline the most recent developments, Fig. 6 shows the average evolution of product and labour market prices in 2000-2012 and 2008-2012. ${ }^{17}$

The striking feature is the fact that nominal wages (as measured by the hourly total labour cost) have always grown above the CPI with hardly any exception, even during the most severe crisis years 2011-2012. Between 2000 and 2007, nominal wages grew by $40 \%$, consumer prices by $20 \%$ and, as a result, real wages grew by around $20 \%$. This figure, therefore, shows that nominal wages, consumer prices and, therefore, real wages, are highly insensitive to the business cycle.

Figure 7 displays the labour market IRFs when the system of Eqs. (1)-(3) is augmented with Eq. (7) so that prices are included in the analysis.

Comparison of the responses by nominal wages (total labour costs) and consumer prices (CPI index) allows to infer the reaction of total compensation in constant terms through the dynamics of its two components. Due to restricted availability of data regarding the total labour costs, we are bound to reduce the system estimation for the first period to years 2000-2007, which implies loosing a third of the sample period (16 quarters of information). This is not the case when using the CPI index and we thus have a natural robustness check. More precisely, comparison of Fig. 7a-c allows us to discard any significant bias resulting from the shortening of the sample period. This reassures us regarding the results for the second period, which is shorter by definition.

The average regional labour market response across the four different models (Fig. 7a-d) yields a substantive robust picture. Although consideration of total costs cause larger long-run relative regional employment effects, it is clear that the qualitative response in terms of the three adjustment mechanisms remains much alike

\footnotetext{
17 It is worth noting that despite these price evolutions are presented at a national level, their patterns are alike across Spanish regions. The purpose of this figure, therefore, is to inform about the economic context in which the impact of the shock will be studied regarding its price effects. We start in 2000 since the total labour cost series is only available 2000 onwards, and we need full comparability across series.
} 

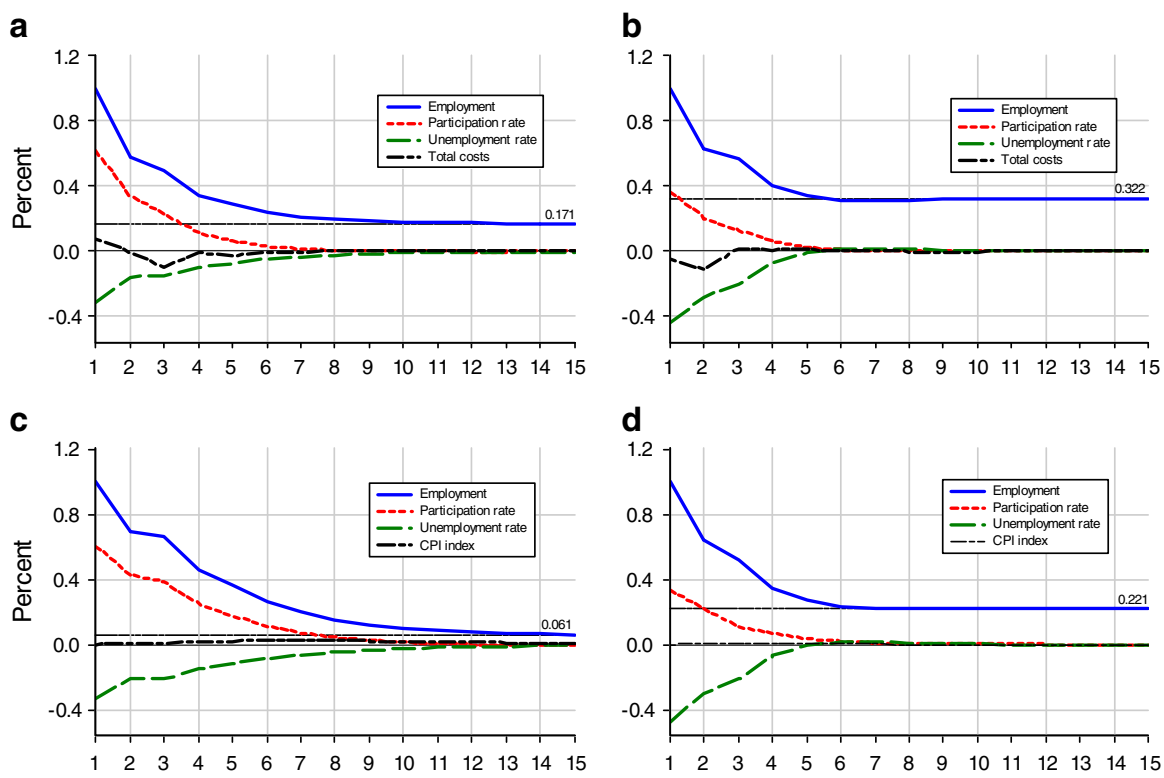

Fig. 7 IRFs to a regional employment shock in total costs and product prices. a Total costs, 2000-2007, b total costs, 2008-2012 , c CPI index, 1996-2007, d CPI index, 2008-2012

across periods and price variables: general asymmetric responses, with participation rates acting as main adjustment channel in expansion, unemployment in recession, and a larger long-run employment level in 2008-2012 pointing to an enhanced relevance of the spatial mobility channel when the shock takes place in troublesome times.

Regarding prices, we confirm that price rigidities are not just present at the national level, but are also a regional matter. This was outlined in Jimeno and Bentolila (1998) for a sample period running from 1983 to 1988, and for real and nominal wages. Nominal wages have thus been considered as a main source of price rigidities in Spanish regions. Here, we further extend this result by disentangling the real wage in its two components. One of the contributions of our work, in this context, is the finding that price rigidities cannot be ascribed just to nominal wages, but also to the behaviour of prices. ${ }^{18}$

The implication of this finding is that the product and labour market reforms that have been passed since the mid 1990s have been essentially unsuccessful in increasing price flexibility. This result is complementary to the one claiming that labour adjustments in Spain are mainly achieved by adjusting temporary work in a labour market that is neatly segmented since the early 1990s (Dolado et al. 2002) in contrast to other European economies (Sala et al. 2012). And this result, in addition, helps to explain the virtual lack of labour market and product market price adjustments.

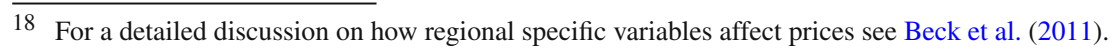


a

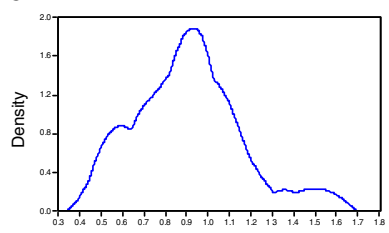

d

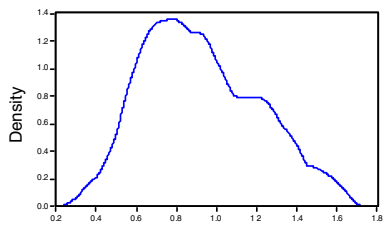

b

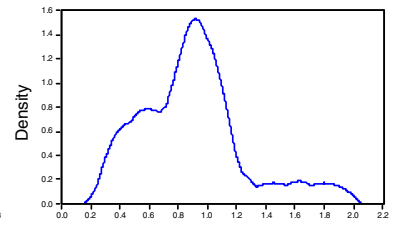

c

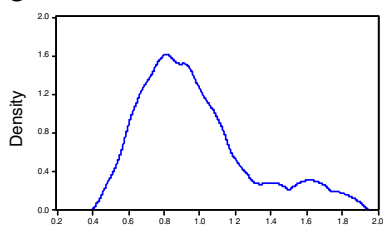

e

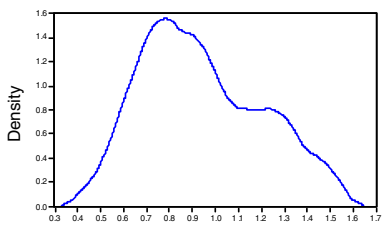

Fig. 8 Kernel density functions: relative unemployment rates. a Kernel density 1996, b Kernel density 2000, c Kernel density 2005, d Kernel density 2010, e Kernel density 2012. Notes Densities estimated with an Epanechnikov kernel. Results are robust to different kernel methods. Source Spanish Labour Force Survey (EPA)

\section{Cluster analysis and regional specificities}

Beyond the differences along business cycle phases, a number of studies point out that Spanish regional unemployment could be regionally clustered into high and low unemployment regions-López-Bazo et al. (2005), Bande et al. (2008), Bande and Karanassou (2009, 2013a,b), and López-Bazo and Motellón (2013). In this spirit, we next test for the existence of significant differences in the regional adjustment mechanisms in high and low unemployment regions when the analysis is performed on regional relative variables (as it is done here, in contrast to the mentioned studies, which focus on absolute regional variables).

\subsection{Cluster analysis}

We follow Bande et al. (2008), and subsequent articles by Bande and Karanassou $(2009,2013 a, b)$, and proceed in two steps. In the first one we use kernel density function analysis to uncover potential clusters in the Spanish regional relative unemployment rates. ${ }^{19}$ In a second step, we perform a $k$-mean cluster analysis based on exogenous variables to rank each region in one of the groups.

Figure 8 depicts the estimated functions for several years. In 1996, most regional rates were slightly below the national unemployment rate, with two small groups in each extreme of the distribution. Then, as the analysis moves forward in time, two groups become clearly distinguishable. A "low unemployment group", where most of the regions take values around 0.8 , and a "high unemployment group" with values around 1.25 .

19 The regional relative unemployment rates are obtained by dividing each regional unemployment rate over the national one. A unit value, therefore, implies equal regional and national unemployment rates. 
Table 8 Composition of groups from the cluster analysis

\begin{tabular}{|c|c|c|c|c|}
\hline & \multicolumn{2}{|c|}{ Group 1} & \multicolumn{2}{|c|}{ Group 2} \\
\hline Andalusia & \multicolumn{2}{|c|}{ Castile-La Mancha } & \multicolumn{2}{|c|}{ Catalonia } \\
\hline Aragon & \multicolumn{2}{|c|}{ Valencian Community } & \multicolumn{2}{|c|}{ Madrid Community } \\
\hline Asturias & \multicolumn{2}{|c|}{ Extremadura } & \multicolumn{2}{|c|}{ Navarre } \\
\hline Balearic Islands & \multicolumn{2}{|c|}{ Galicia } & \multicolumn{2}{|c|}{ Basque Country } \\
\hline Canary Islands & \multicolumn{2}{|c|}{ Murcia } & & \\
\hline Cantabria & \multicolumn{2}{|c|}{ La Rioja } & & \\
\hline \multicolumn{5}{|l|}{ Castile-Leon } \\
\hline & Mean & $\mathrm{SD}$ & Mean & SD \\
\hline Activity rate & 0.555 & 0.049 & 0.595 & 0.031 \\
\hline Relative total labour costs ${ }^{\mathrm{a}}$ & 0.906 & 0.065 & 1.142 & 0.051 \\
\hline Relative unemployment rate & 0.989 & 0.301 & 0.715 & 0.139 \\
\hline
\end{tabular}

$S D$ Standard deviation, data sources as explained in Table 1

${ }^{a}$ Analysis restricted to $2000 \mathrm{q} 1-2012 \mathrm{q} 3$ due to data availability

These results are similar to the ones obtained by Bande and Karanassou (2009, 2013a,b). Like them, we cluster the Spanish regions in two groups, and proceed to assign each Spanish region to one of them. A tempting procedure would be to allocate the regions according to their regional unemployment rate, given that Figs. 2 and 8 would provide immediate allocations. This, however, would generate a purely endogenous classification, which we want to avoid. Hence the second step.

We conduct a cluster analysis following a $k$-means procedure. ${ }^{20}$ This procedure is based on a selection of exogenous variables, which are used to allocate each region in a single group. We follow the literature and choose two variables closely related to regional social welfare: the participation rate and the relative total labour cost. ${ }^{21}$ Table 8 shows the composition of the two groups and the group averages of the two variables examined.

Group 1 is formed by Andalusia, Aragon, Asturias, Balearic Islands, Canary Islands, Cantabria, Castile-Leon, Castile-La Mancha, the Valencian Community, Extremadura, Galicia, Murcia and La Rioja, whereas Group 2 is formed by just four regions: Catalonia, Madrid Community, Navarre, and the Basque Country. It is worth noting that Group 2 comprises regions with larger participation rates and compensations, and lower relative unemployment rates than the regions in Group 1. Thus, from now one we refer to Group 2 as the "low unemployment group" and to Group 1 as the "high unemployment group".

Once the two groups are identified, the next step is to create regional specific variables for each group in which the reference mean is the one of the group in which each region has been allocated. Then, in order to be consistent with our methodology, we follow Broersma and van Dijk (2002) and regress again Eqs. (4) to (6), but this

\footnotetext{
20 For a detailed description of cluster analysis, see Everitt et al. (2001) and Bande et al. (2008).

21 Although it is frequent to choose relative per capita income, our closest measure at hand to a quarterly and recent regional measure of social welfare is total compensation.
} 

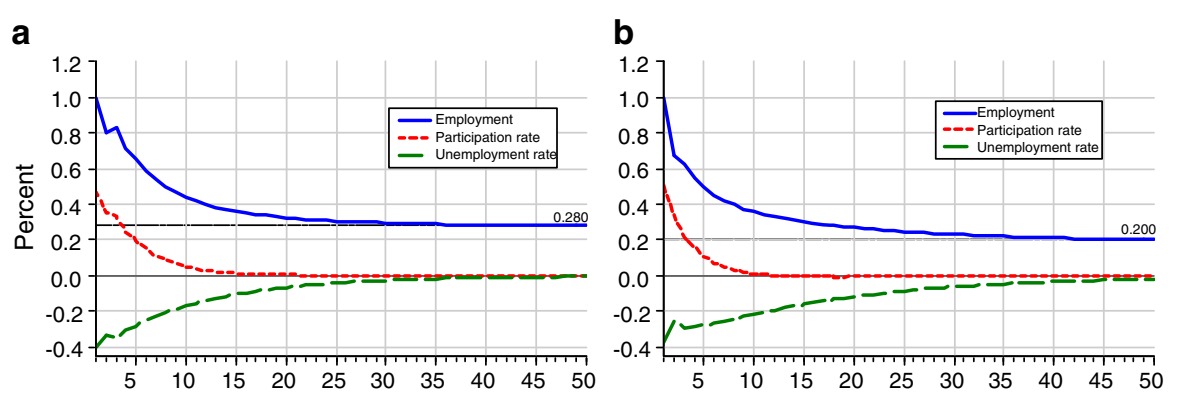

Fig. 9 IRFs to a regional employment shock in Groups 1 and 2 of regions. a Group 1 of regions, 1996-2012, b Group 2 of regions, 1996-2012

time considering two average regions: one representing those in Group 1 and another one representing those in Group 2.22

\subsection{Regional specificities}

Figure 9 shows the IRFs corresponding to the high and low unemployment rate groups. $^{23}$

The first noticeable result is the similarity in the dynamic response of the participation rates and employment levels in both groups of regions to a regional employment shock (the employment response being slightly larger than for the high unemployment regions). The group of high unemployment regions (Group 1) responds in a similar way than the Spanish regions when considered all together, and achieves a long-run, relative regional employment level that is increased by $28 \%$ (quite close to the aggregate rise of $27.3 \%$ ). In turn, the group of low unemployment regions (Group 2) responds in a slightly softer way with a rise of $20.0 \%$.

In addition, even though both groups of regions deliver an almost identically shortrun response to the shock, we find unemployment persistence to be larger in the long-run in the low employment regions, where convergence takes around 40 periods (instead of 35 in high unemployment regions).

These results have important implications. The fact that both groups share similar dynamic adjustments in terms of participation rates and employment levels, but unemployment rates are more persistent in "low unemployment" regions, implies that spatial mobility is more relevant to explain relative adjustments in the "high unemployment" regions. Consequently, absolute differences between the regional unemployment rates of these groups should be ascribed to either regional structural differences, to nationwide shocks producing different impacts, or to both circumstances. Not, in any case, to different responses to one-off regional employment shocks.

\footnotetext{
22 Note that we do not combine time and regional disaggregation simultaneously. The reason is the tight amount of degrees of freedom in which this analysis is conducted, which would be problematic in case of estimating Eqs. (4) to (6) for Group 2 containing only four regions, for the restricted sample period 2008-2012.

23 To conserve space, the results of the new estimation of Eqs. (4) to (6) for each group are not reported.
} 
Table 9 IRFs decomposition to a $1 \%$ regional employment shock in high and low unemployment regions

\begin{tabular}{|c|c|c|c|c|c|c|}
\hline & \multicolumn{3}{|c|}{ Group 1 (1996-2012) } & \multicolumn{3}{|c|}{ Group 2 (1996-2012) } \\
\hline & $\begin{array}{l}\text { Participation } \\
(\%)\end{array}$ & $\begin{array}{l}\text { Unemployment } \\
(\%)\end{array}$ & $\begin{array}{l}\text { Migration } \\
(\%)\end{array}$ & $\begin{array}{l}\text { Participation } \\
(\%)\end{array}$ & $\begin{array}{l}\text { Unemployment } \\
(\%)\end{array}$ & $\begin{array}{l}\text { Migration } \\
(\%)\end{array}$ \\
\hline Year 1 & 42 & 42 & 16 & 43 & 42 & 15 \\
\hline Year 2 & 24 & 42 & 34 & 14 & 59 & 27 \\
\hline Year 3 & 11 & 38 & 52 & 2 & 60 & 38 \\
\hline
\end{tabular}

Quarterly data aggregated to annual values and normalised by the employment response in the year

This result can be checked, numerically, in Table 9. While in regions with relative high unemployment rates there is a much stronger tendency to leave and there is large spatial mobility, low employment regions are more resilient, and the shock causes larger adjustments in the unemployment rates.

We find this result consistent with the one we have obtained in Sect. 5, when splitting the sample period to distinguish the wild-ride from the steep-fall years. We uncovered a stronger tendency to migrate in bad times which, according to these new set of results, may be connected to the fact that people face a relatively bad period (such as the 2008-2012 one), or to the fact that they live in a region with a relatively high unemployment rate.

\section{Conclusions}

How does the labour market of the average Spanish region respond to an employment shock? Is this response symmetric across business cycle phases? How do prices adjust in response to such shocks? Do regions react alike in spite of their unemployment rate differences? These are the central questions we have tried to answer.

Our aggregate analysis shows that persistence in the Spanish regional labour market is not substantially different today than in 1976-1994, as documented by Jimeno and Bentolila (1998). Although the Spanish labour market may be, on aggregate, much more flexible than it was, there has been little progress in terms of regional unemployment persistence (recall Fig. 2b). The main difference lies in the larger adjustment, today, through changes in participation rates, although with a lower degree of persistence.

We also find evidence of different responses across business cycle phases. The main mechanism to adjust to a regional shock in expansion is the change in the participation rate, whereas unemployment and migration become the central ones in recession (in the short- and long-run, respectively).

Another finding is that the long-run relative employment level in the aftermath of the shock is higher in 2008-2012 than in 1996-2007. This is an outcome of the growing relevance, in the second period, of the migration adjustment mechanism to regional shocks. Although it is well-known that the Spanish labour market is not characterised by a high degree of regional mobility since the 1970's, our results provide support to the hypothesis that people in a particular region have become more willing to migrate 
(relative to the national average) when confronted to a shock that takes place in a recessive context than when confronted to an equivalent shock taking place in good times.

We also find that price stickiness is still very strong nowadays (1996-2012), a result that should come as no surprise since this was already documented by Jimeno and Bentolila (1998). Our contribution on this regard is that strong real wage rigidities arise both from nominal wages and consumer prices, and are present both in expansion and recession. This seems to indicate that the product and labour markets are still operating with a substantial degree of imperfect competition, in which case policy measures implemented to foster competition and a larger responsiveness of market prices to the changing (regional) economic environment have, to a large extent, failed to achieve their target.

Disaggregation of the Spanish regions by groups uncovers very similar responses in the short-run, and some divergence as time goes by. In the long-run, high unemployment regions are more reactive in terms of spatial mobility. This reveals a larger propensity to migrate from regions with high than from regions with low unemployment rates. It follows that differences in regional unemployment need to be explained by factors other than regional labour market dynamics. For example, by differences in regional amenities, or different responses to nation-wide shocks.

In any case, we need time to reduce our unemployment rate-participation rate is the main adjustment mechanism in good times-, but we are quick in rising it unemployment becomes the most important adjustment channel in troublesome times. Given the current difficulties in reducing unemployment, this is an asymmetry that will surely receive attention in future work.

Acknowledgments We gratefully acknowledge the insightful comments and suggestions received from two anonymous referees. We are grateful to the Spanish Ministry of Economy and Competitiveness for financial support through grant ECO2012-13081.

Open Access This article is distributed under the terms of the Creative Commons Attribution License which permits any use, distribution, and reproduction in any medium, provided the original author(s) and the source are credited.

\section{References}

Alecke B, Mitze T, Untiedt G (2010) Internal migration, regional labour market dynamics and implications for German East-West disparities: Results from a Panel VAR. Rev Reg Res 30(2):159-189

Altissimo F, Bilke L, Levin A, Mathä T, Mojon B (2009) Sectoral and aggregate inflation dynamics in the Euro area. J Eur Econ Assoc 4:585-593

Bande R, Fernández M, Montuenga V (2008) Regional unemployment in Spain: disparities, business cycle and wage-setting. Labour Econ 15(5):885-914

Bande R, Fernández M, Montuenga V (2010) Desequilibrios territoriales en el mercado laboral y estructura de la negociación colectiva. Papeles de Economía Española 124:193-213

Bande R, Karanassou M (2009) Labour market flexibility and regional unemployment rate dynamics: Spain 1980-1995. Pap Reg Sci 88(1):181-207

Bande R, Karanassou M (2013a) The NRU and the evolution of regional disparities in Spanish unemployment. Urban Stud 50(10):2044-2062

Bande, R, Karanassou M (2013b) Spanish regional unemployment revisited: the role of capital accumulation. Reg Stud. doi:10.1080/00343404.2013.779657

Beck GW, Hubrich K, Marcellino M (2011) On the importance of sectoral and regional shocks for pricesetting. In: ECB working papers, no 1334 
Blanchard OJ, Katz LF (1992) Regional evolutions. Brook Pap Econ Act 1:1-75

Bover O, Arellano M (2002) Learning about the migration decisions from the migrants: using complementary datasets to model intra-regional migrations in Spain. J Popul Econ 15(2):357-380

Broersma L, van Dijk J (2002) Regional labour market dynamics in the Netherlands. Pap Reg Sci 81:343364

Decressin J, Fatás A (1995) Regional labour market dynamics in Europe. Eur Econ Rev 39:1627-1655

Dolado JJ, García-Serrano C, Jimeno JF (2002) Drawing lessons from the boom of temporary jobs in Spain. Econ J 112(721):F270-F295

Elhorst JP (2003) The mystery of regional unemployment differentials: theoretical and empirical explanations. J Econ Surv 17(5):709-749

Everitt B, Landau S, Leese M (2001) Cluster analysis. Arnold, London

Fisher RA (1932) Statistical methods for research workers, 4th edn. Oliver \& Boyd, Edinburgh

Fredriksson P (1999) The dynamics of regional labor markets and active labor market policy: Swedish evidence. Oxf Econ Pap 51:623-648

Jimeno JF, Bentolila S (1998) Regional unemployment persistence (Spain, 1976-1994). Labour Econ 5:2551

L'Angevin C (2007) Dynamiques d'ajustement et mobilite du travail au sein de la zone euro. Economie et Prévision 178-179(2-3):149-157

Levin A, Lin C, Chu C (2002) Unit root test in panel data: asymptotic and finite-sample properties. J Econ 108:1-24

López-Bazo E, Del Barrio T, Artís M (2005) Geographical distribution of unemployment in Spain. Reg Stud 39:305-318

López-Bazo E, Motellón E (2012) Human capital and regional wage gaps. Reg. Stud 46:1347-1365

López-Bazo E, Motellón E (2013) The regional distribution of unemployment: what do micro-data tell us? Pap Reg Sci 92(2):383-405

Love I, Zicchino L (2006) Financial development and dynamic investment behavior: evidence from panel VAR. Q Rev Econ Financ 46(2):190-210

Maddala GS, Wu S (1999) A comparative study of unit root tests with panel data and new simple test. Oxf Bull Econ Stat 61:631-652

Mäki-Arvelaa P (2003) Regional evolutions in Finland: panel data results of a VAR approach to labour market dynamics. Reg Stud 37(5):423-443

Marston S (1985) Two views of the geographic distribution of unemployment. Q J Econ 100:57-79

Mauro P, Spilimbergo A (1999) How do the skilled and the unskilled respond to regional shocks? The case of Spain. IMF Staff Pap 46(1):1-17

Moran PAP (1950) Notes on continous stochastic phenomena. Biometrika 37:17-23

Murillo IP, Núñez F, Usabiaga C (2006) Persistencia del desempleo regional: El caso del sur de España. Revista de Economía Laboral 3(1):46-57

Sala H, Silva JI, Toledo M (2012) Flexibility at the margin and labor market volatility in OECD countries. Scand J Econ 114(3):991-1017

Sala H, Trivín P (2013) Labour market dynamics in Spanish regions: evaluating asymmetries in troublesome times. In: IZA Discussion Paper no. 7746, IZA, Bonn 